\title{
Approach to an Ulcer of Venous Etiology in a Primary Care Nursing Consultation
} \author{
Olga Morales Abajo and Noelia Pueyo Royo \\ Health Center Romareda Seminar, Spain \\ *Corresponding author: María José Gil Mosteo, Health Center Romareda Seminar, Spain
}

María José Gil Mosteo*, Ruben García Muñío, Arturo Miravet Gómez, Belen Torres Trasobares,

\section{ARTICLE INFO}

Received: 催 April 02, 2021

Published: 幽 April 20, 2021

\section{ABSTRACT}

Citation: María José Gil M, Ruben García M, Arturo Miravet G, Belen Torres Tr, Olga Morales A, Noelia Pueyo R. Approach to an Ulcer of Venous Etiology in a Primary Care Nursing Consultation. Biomed J Sci \& Tech Res 35(2)-2021. BJSTR. MS.ID.005669.

\section{Introduction}

Ulcers of the lower extremities constitute a significant health problem that carries both socioeconomic and health repercussions; as great consumption of human and material resources. They are defined as a spontaneous or accidental lower extremity injury whose etiology may be due to a limb or systemic disease process and which does not heal in the expected time interval [1]. The ulcer of venous etiology (UEV) is due to a defect of substances in the pathologically altered tissue of the leg, being the most serious complication of chronic venous insufficiency (CVI). The lower extremity ulcer (UEII) affects $1 \%$ of the adult population, $3.6 \%$ in those over 65 years and $5 \%$ in those over 80 years. They are more prevalent in women than in men, with a ratio of 7:10 and both multiply $x 2$ if the age segment $>65$ years.

In Spain, the prevalence of ulcers of venous etiology is between $0.5-0.8 \%$, while arterial ulcers range between 0.2 and $2 \%$ [2]. UEVs are the most prevalent, representing $75-80 \%$ of the total, affecting $1-2 \%$ of the world population. They also represent a high expense for the National Health System, due to their frequent chronicity and high recurrence rate; partly in the last decade, due to the lack of consensus among the different professionals and high diagnostic and / or therapeutic variability. The direct and indirect costs of the UEII represent between $1.5-3 \%$ of the total budget of the National Health Systems in the European Union. It is necessary to approach it from a holistic point of view, considering its prevention and a comprehensive care plan. Primary Care Nursing plays a fundamental role in its prevention, controlling risk factors: Smoking, diabetes, dyslipidemia and HT; in the UEA, and the predisposing factors of the UEV: age $>65$ years, sex (female), Caucasian race, activity, obesity and hereditary factors.

In a patient with UEV, compression therapy is the cornerstone of treatment and is considered the standard first-line clinical treatment. Whenever possible, multi-component compression bandages will be the first treatment option [3]. The effects of compression on reduction of edema and pain, its ability to increase cure rates; They have been highlighted in the scientific literature through several systematic reviews, also highlighting their benefits with respect to their recurrence. However, in Spain, only 1 in 6 people $(53,000)$ with UEV are treated with compression therapy [4]. Addressing a wound of this etiology without knowing the determining role of compression in its evolution would lead the patient to the chronicity of the injury and prolong the healing process. To achieve the best results in these treatments, it is essential to have the cooperation of the patient.

\section{Aim}

Describe the effectiveness of compression therapy in the treatment of ulcers of venous etiology.

\section{Methodology}

A 50-year-old patient came to the clinic due to a torpid evolution wound in the lower limb due to trauma, being treated by the patient himself with povidone iodine for two months. 


\section{Anamnesis}

No relevant medical history, no drug allergies, currently not taking drug treatment, smoker of 10 cigarettes a day, and works as a waiter.

\section{Physical Examination}

Presents chronic venous insufficiency, according to CEAP classification, C6: skin changes with active ulcer.

\section{7-11-2020}

The wound bed shows $10 \%$ wet necrosis, 30\% fibrin, the remainder of granulation tissue with abundant exudate, ocher dermatitis all over the limb. After palpation of pulses and with an $\mathrm{ABI}=1$, the importance of applying compression therapy to treat the cause of the wound and achieve healing is explained to the patient.

The patient accepts the treatment, the first treatment is performed with a hydrodetersive dressing plus a non-adhesive hydrocellular dressing and a multicomponent bandage, and an appointment is made at $24 \mathrm{~h}$ to check tolerance to the bandage. Although the patient manifested discomfort, such as itching, heat, and discomfort, the results at $24 \mathrm{~h}$ were remarkable; granulation tissue appearing in $70 \%$ of the wound bed with decreased exudate. It insists on the convenience of continuing with compression therapy and cures are performed every 48-72 $\mathrm{h}$ agreed with the patient (he could not resist wearing the bandage any longer). At 3 weeks after treatment, the wound has reduced in size and presents granulation tissue in practically the entire bed, so the cure is changed: metalloprotease modulator dressing plus multicomponent bandage [5-7].

\section{Results}

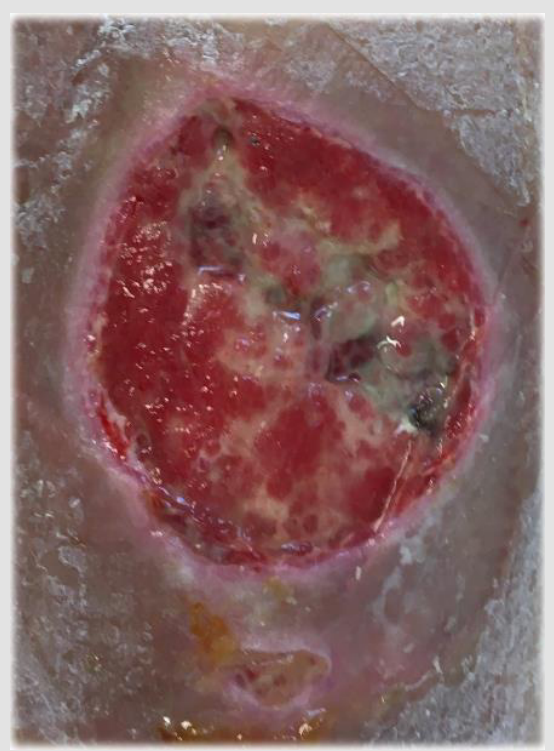

Figure 1.

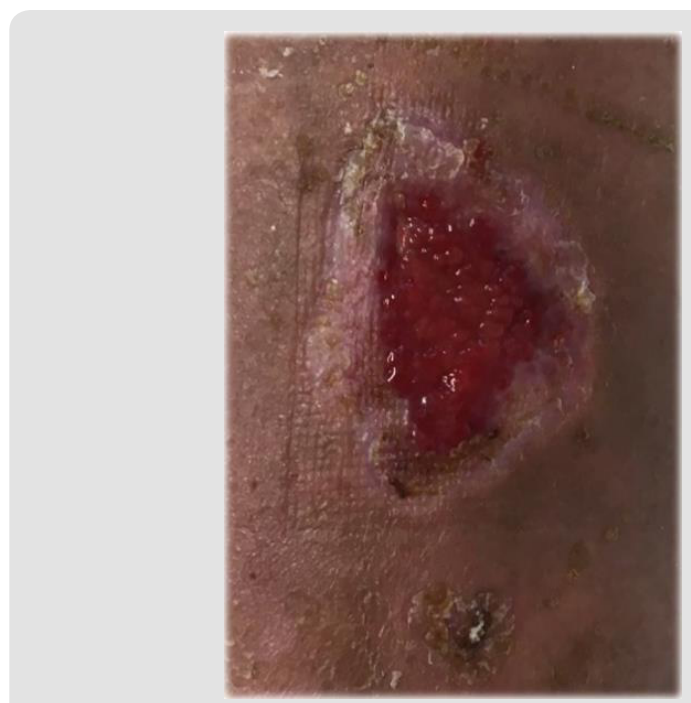

Figure 2.

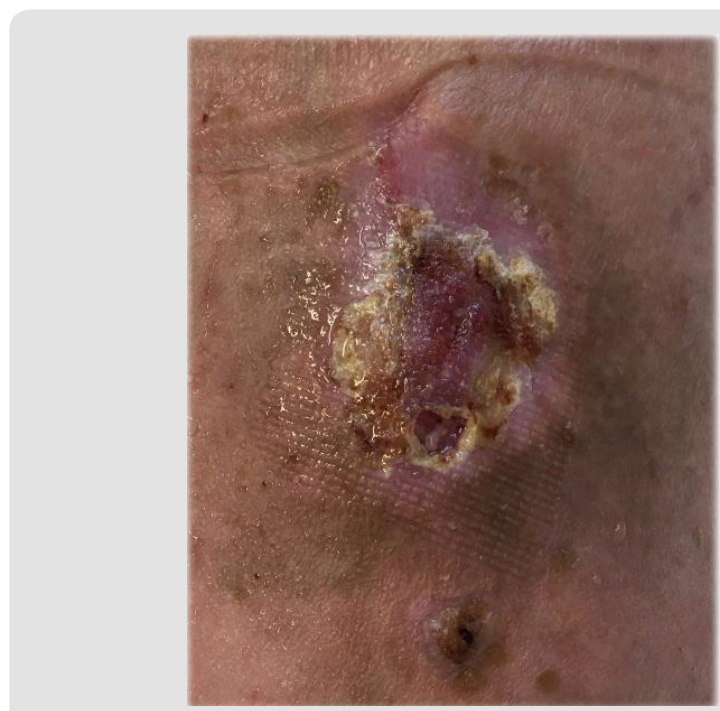

Figure 3.

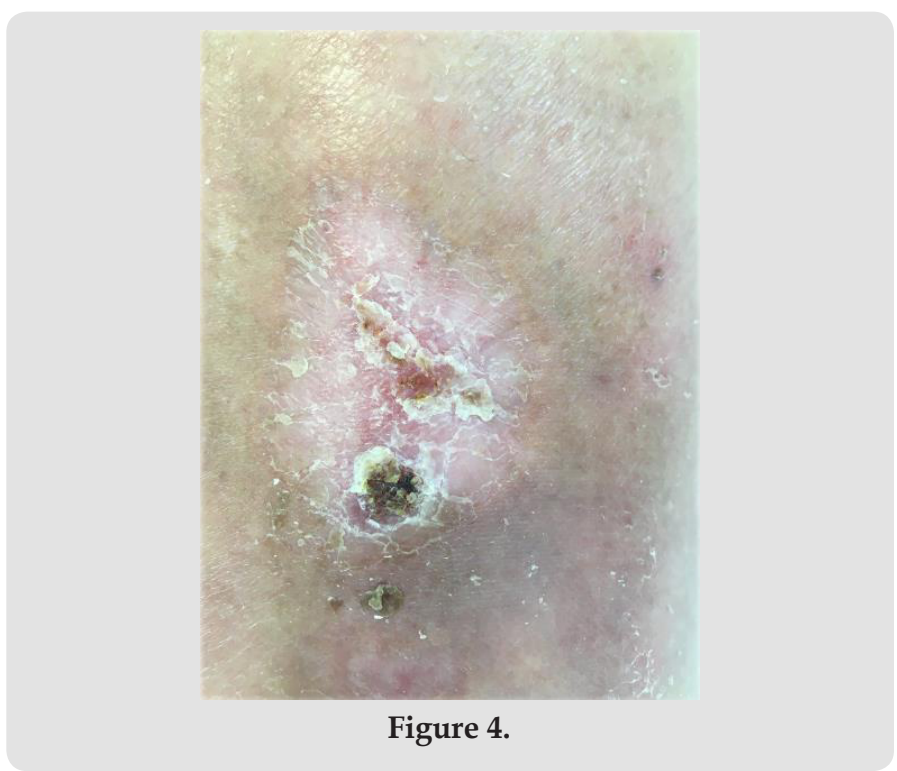


Total healing was achieved in less than 2 months of treatment, the ocher dermatitis disappeared in the entire limb, the quality of life of the patient improved, who was discharged from the hospital and returned to work.

A compression sock was prescribed, and recommendations were given to avoid recurrences, such as abandoning toxic habits, exercise and postural hygiene [8-10] (Figures 1-4).

\section{Conclusion}

The multicomponent compression therapy together with the adherence of the patient to the treatment, have been fundamental for the healing of this ulcer of venous etiology in such a short period of time. We can affirm that compression therapy is the gold standard in the treatment of ulcers of venous etiology.

\section{References}

1. MarinelIo J, Verdú J (2018) National Consensus Conference on Lower Extremity Ulcers (C.O.N.U.I). $2^{\text {nd }}$ (Edn.), Madrid: Ergon, p. 48-64.

2. Weller CD, Richards C, Turnour L, Team V (2021) Venous leg ulcer management in Australian primary care: Patient and clinician perspectives. Int J Nurs Stud 113: 103774.

3. Lurie F, Bittar S, Kasper G (2018) Optimal Compression Therapy and Wound Care for Venous Ulcers. Surg Clin North Am 98(2): 349-360.

ISSN: 2574-1241

DOI: $10.26717 /$ BJSTR.2021.35.005668

María José Gil Mosteo. Biomed J Sci \& Tech Res

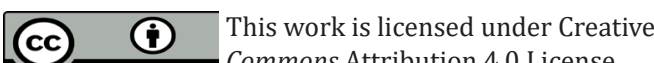

Submission Link: https://biomedres.us/submit-manuscript.php
4. Jimenez García JF, Aguilera Manrique G, Arboladas Bellon J, Gutiérrez García M, González Jiménez F, et al. (2019) The effectiveness of Advanced Practice Nurses with Respect to Complex Chronic Wounds in the Management of Venous Ulcers. Int J Environ Res Public Health 16(24): 5037.

5. Rueda López J, Torra Bou JE, Martinez Cuervo F, Verdú Soriano J, Soldevilla Agreda JJ, et al. (2004) First National Study of the Prevalence of Leg Ulcers in Spain. GNEAUPP-UICF-Smith \& Nephew 2002-2003 study. Epidemiology of Venous, Arterial, Mixed, and Diabetic Foot Ulcers 15(4): 230-247.

6. Guinot Bachero J, Balaguer López E, García Molina P (2019) EDIPO study: wounds in the lower extremities. How do nurses approach their management?. p. 51-57.

7. (2017) Spanish Association of Vascular Nursing and Wounds. Clinical practice guide: Consensus on vascular ulcers and diabetic foot [Internet]. $3^{\text {rd }}$ (Edn.), Madrid: AEEVH.

8. (2016) Sergio San Jordán Foundation for Research and Study of Chronic Wounds. National Group for the study and advice on Pressure Ulcers and Chronic Wounds. Comprehensive Care of Chronic Wounds. $2^{\text {nd }}($ Edn.), Logroño.

9. Miquel Abbad C, Rial Horcajo R, Ballesteros Ortega, García Madrid C (2015) Clinical practice guide in chronic venous disease. Torrejón de Ardoz: IDMédica.

10. (2021) Clinical Practice Guidelines in Chronic Venous Disease-GNEAUPP.

$\begin{array}{ll}\text { BIOMEDICAL } & \text { Assets of Publishing with us } \\ \text { RESEARCHES } & \text { - Global archiving of articles } \\ \text { - Immediate, unrestricted online access }\end{array}$

